\title{
Adverse effects of a natural product allowing decreasing the amount of cholesterol in blood; A study using ants as models
}

\begin{abstract}
Hypercholesterolemia is nowadays one of the most widespread pathology. It is treated using statins (for instance, simvastatin) which have, however, several harmful effects. Having confirmed such effects working on ants as models, we here used again ants for examining the adverse effects of the natural red yeast of rice, a food additive which contains a statin, the lovastatin. The product used (arterin) slightly increased the ants' intake of sugar food comparatively with meat intake, slightly decreased their activity, slightly increased their sinuosity of movement, decreased their trail following behaviour, tactile perception, cognition, ability in escaping from an enclosure, as well as their visual and olfactory conditioning and memory. Arterin did not impact the ants' orientation ability, audacity, brood caring, aggressiveness against nest mates and aliens. Adaptation occurred for some adverse effects, habituation to the physiological impact did not occur, and ants developed no dependence on that food additive. The effects of arterin slowly decreased in 25 hours. On the whole, arterin presented less adverse effects than simvastatin, and those presented were of lower intensity. The red yeast of rice should thus be used preferentially to manufacture statins for treating predominating persons suffering from moderate hypercholesterolemia.
\end{abstract}

Keywords: arterin, cognition, locomotion, memory, statins, hypercholesterolemia
Volume I Issue 3 - 2017

\author{
Marie Claire Cammaerts \\ Department of Organizational Biology, Free University of \\ Brussels, Belgium
}

Correspondence: Marie-Claire Cammaerts, Department of Organizational Biology, Free University of Brussels, Independent researcher, 27, Square du Castel Fleuri, I I 70, Brussels, Belgium, Tel 322673 4969,

Email mtricot@ulb.ac.be, mccammaerts@gmail.com

Received: June 01, 2 017 | Published: June 15, 2017
Abbreviations: ang.deg, angular degrees; ang.deg./cm, angular degrees per $\mathrm{cm} ; \mathrm{mm} / \mathrm{s}$, millimeter per second; $\chi^{2}$, chi square; vs, versus; $\mathrm{n}^{\circ}$, number; $\mathrm{cm}$. centimetre; $\mathrm{mm}$, millimeter; $\mathrm{ml}$, milliliter; $\mu 1$, micro liter; mg, milligram; $\mathrm{S}$, second; min, minute: $\mathrm{H}$, hours; $t$, time; \%. percentage

\section{Introduction}

Nowadays, hypercholesterolemia is a frequent pathology which must be treated since it may lead to dangerous diseases such as cardio vascular accident, infarcts, and any health problems due to poor blood flow. Drugs have thus been produced for caring of these patients. The most used drugs are the statins. These substances inhibit the enzyme hydroxymethylglutaryl $\mathrm{CaA}$ reductase (HMG-CoA reductase) which acts during the synthesis of cholesterol, and they are thus very efficient in reducing the amount of cholesterol in blood. However, after having used for a long time without warnings, statins were found to have several adverse effects (or were finally notified to have such effects). ${ }^{1}$ We studied the harmful impacts of simvastatin, a commonly used statin, and discovered that, effectively this drug impacts the sugar intake, the active state, the locomotion capacities, the memory, the cognition and the audacity. ${ }^{2}$ Many persons under a statin treatment even become intolerant of that drug and finally stop consuming it. ${ }^{3}$ New drugs allowing treating hypercholesterolemia were thus researched, and a new one has recently been found. This new drug is a monoclonal antibody which stops the activity of the enzyme PCSK9 which prevents the degradation of cholesterol. Under the new drug treatment, cholesterol is thus degraded. The new drug is commercialized under several labels (alirocumat, repatha, praluent) and is really very efficient in reducing the amount of cholesterol in blood. However, being an antibody, acting on an enzyme (thus possibly on other ones), and going to be very largely sold, ${ }^{4}$ it is highly probable that it has adverse effects and that these effects have not (yet) been divulgated. There exists another natural product which may help keeping a low level of cholesterol in blood: the red yeast of rice. It is a food complement, known since a very long time, efficient for treating hypercholesterolemia, and having, at first sight, no adverse effect. ${ }^{5}$ This food complement is efficient because it contains a statin, the lovastatine, one of the six commercialized statins. ${ }^{6}$ However, the red yeast of rice has recently been found to have some harmful effects. ${ }^{7}$ Are these effects severe? Are they as severe as those of simvastatin? Are they severe enough for preventing humans to use that natural food complement? Having previously studied the impact of simvastatin, we aimed to examine those of the red yeast of rice, applying same methods, with ants as models just like for simvastatin.

In this introduction, we first defend our use of ants, which species we used, what we know about it, as well as what we intended to study; then we precise the food complement containing red yeast of rice we used and what can be learned on it. Most biological processes (i.e. food intake, chemical biological reactions, learning, memory, muscles functioning etc.) are common to every animals. Consequently, several ones served as models for exploring biological processes. ${ }^{8}$ Invertebrates are increasingly employed since their life cycle is short lasting, their morphology is rather simple, and they are generally numerously available. ${ }^{9}$ Some species are widely used (see details in $^{9}$ ). Insects are often used (i.e. Apis mellifera). ${ }^{10}$ Ants could also serve as models. They are eu social insects; they are evolved as for their society organization, their behavior, their anatomy, and their physiological capabilities. They have an evolved resting position of their moth parts, ${ }^{11}$ and possess numerous glands producing pheromones. ${ }^{12}$ Their societies present some division of labor, agebased polyethism and adaptation to perturbations. ${ }^{13}$ They take care of their larvae and nymphs, they construct adequate nests, and they 
imbibe their life environment (inside of nest, surroundings, given areas) with appropriate secretions. ${ }^{13}$ They can employ alarm, trail and recruitment signals $;{ }^{14}$ they can use learned cues for navigating: $;{ }^{14}$ they can recruit nestmates in due time, ${ }^{13,14}$ and they remove rubbish from their nest. ${ }^{13,14}$ Given their biology, it is possible to employ them for examining the impacts of products, or events on several biological functions. Also, several nests made of hundreds of individuals can easily be kept during the entire year in a laboratory,

We study ants since 1969 , working essentially on those belonging to the genus Myrmica. As for Myrmica sabuleti Meinert 1861, we know partly its ecology, vision, navigation, conditioning abilities, and recruitment. ${ }^{15}$ We have also examined the acquisition of some abilities by callows. ${ }^{16}$ A given study ${ }^{17}$ revealed that these ants could be excellent models. Effectively, they were so while examining on them the impacts of substances consumed by humans (products, drugs, antidepressants, food additives, anxiolytics) ${ }^{18}$ For each of the studies substances, we found impacts also seen in humans (and could give precise information on them), and we revealed other effects which may exist for humans. In the present work, we again employed M. sabuleti for studying the impacts of a natural food complement which is efficient in reducing the amount of cholesterol in blood. We intended to assess the following 18 ethological and/or physiological traits first as long as ants lived under normal diet, then when they consumed red yeast of rice, and 4 other traits only on ants consuming (or having consumed) that food complement. These $18+4$ traits were:

1. sugar water consumption

2. meat intake

3. active state

4. speed of locomotion

5. sinuosity of movement

6. orientation ability

7. trail-following

8. audacity

9. pain perception

10. brood-caring

11. cognitive ability

12. aggressive behavior towards nestmates

13. aggressiveness against aliens

14. ability of escaping from a trap

15. visual conditioning ability

16. visual memory

17. olfactory conditioning ability

18. olfactory memory

19. adaptation to the food complement consumption

20. habituation to the food complement effects

21. dependence on the food complement use

22. decrease in the effects of the food complement after weaning
Which food complement did we use and which information can one get about it? We used the food complement 'arterin' commercialized by Sandoz, the most usually consumed red yeast of rice. Leaflets joined to the package of arterin inform that this food complement efficiently allows keeping a low level of cholesterol, has no adverse effect, but is not recommended for children and pregnant women. This information is similar to what can be found on internet, in easily available links such as www.omega-pharma.fr/produit.php?docid=1668; https:// www.pharmaclic.be > ... > Complements alimentaires > Cholesterol. Looking more attentively to specialized links, researching informative details on the product, one can discover that the red yeast of rice, including arterin, may induce some weak though not negligible adverse effects such as headache, pain in muscle, and tiredness. Very few works exist, and are poorly divulgated, about the effects of the red yeast of rice. Persons consuming this food additive surely ignore these effects, and thus, even if suffering from them, do not attribute them to the red yeast of rice. Given this situation, and our previous work on the effects of statins, ${ }^{2}$ we had to comparatively study those of the red yeast of rice, explore the bibliography about this product and clarify its safety state. The present paper relates this work, made on ants as models

\section{Material and methods}

\section{Collection and maintenance of ants}

We worked on two colonies of M. sabuleti found in Ardenne (Belgium) in June 2016. The ants nested under stones; the colonies contained 500-800 workers, 1-2 queens and brood. We kept them in 2-3 glass tubes half filled with water and plugged with cotton. The nest tubes were set in trays $(34 \mathrm{~cm} \times 23 \mathrm{~cm} \times 4 \mathrm{~cm})$, the sides of which had previously been covered with talc to avoid ants escaping. The trays were the ants' foraging areas; food was provided there. The ants were fed with sugared water continuously given in tubes (diameter: $1.5 \mathrm{~cm}$, length: $7 \mathrm{~cm}$ ) plugged with cotton, and with cut Tenebrio molitor larvae (Linnaeus, 1758) given three times a week. The temperature equaled $18^{\circ} \mathrm{C}-22^{\circ} \mathrm{C}$, and the humidity about $80 \%$. The intensity of the lighting was 330lux while working on ants. During other time periods, it was provided by natural light and had an intensity of 5-120lux according to the time of the day. The intensity of the electromagnetic field of the laboratory equaled $2-3 \mu \mathrm{W} / \mathrm{m}^{2}$. The workers are often here named nestmates, as do researchers on social insects.

\section{Solution of arterin given to the ants}

A package of 'arterin' Sandoz was furnished by the practitioner Vanlaer (1170, Bruxelles, Belgium). Humans are advised to consume $20 \mathrm{mg}$ or $40 \mathrm{mg}$ arterin per day. Humans, on an average, drink more or less $1,000 \mathrm{ml}$ of water each day (not including the water contained in food). Thus, under arterin diet, they consume, per day, 20 or $40 \mathrm{mg}$ of the food complement and one liter of water. Insects, and thus ants, drink proportionally 10 times less than mammals. Consequently, a solution of $40 \mathrm{mg}$ of arterin in $100 \mathrm{ml}$ water must be given to ants so that they lived under an arterin diet similar to that lived by humans daily. A tablet of $40 \mathrm{mg}$ arterin was thus dissolved in $100 \mathrm{ml}$ of sugar water commonly given to the ants. This solution was delivered to the ants in small tubes used for providing them with sugar water. It was daily checked if ants effectively drunk the solution of arterin, and they did. The cotton plugging the tubes was refreshed every 2-3 days, and a new solution was provided every 7 days. Experiments on ants under arterin diet started after the colonies were provided with the adequate solution since 24 hours. 


\section{Food intake, active state}

The workers taking sugar water, eating the T. molitor larvae, and being in movement anywhere in their nest, around it, near the food sources were counted during six successive days, three times at 12:0015:00 o'clock, and three times at 21:00-24:00 o'clock (west European winter time $=\mathrm{UT}+1)($ Table 1, Daily counts $)$. Each day, we calculated the mean of such counts. The six daily means (Table 1) for ants under arterin diet were compared to the six daily means obtained for these ants while they did not consume that food complement, thanks to the non-parametric test of Wilcoxon. ${ }^{19}$ Moreover, we established the average of the daily means (Table 1) Average of daily means).

Table I Impact of a natural drug against hypercholesterolemia on food consumption and general activity. Assessments were made on ants of colonies A and B under normal diet, then consuming the drug. The ants drinking sugar water, eating meat, and moving at any place of their environment were counted 3 times between 12:00 and 15:00 and 3 times between 21:00 and 24:00 (Daily counts), during 6days. Daily means, and the average of the daily means were established. Statistical results are given in the text. Briefly, ants consuming the drug proportionally consumed more sugar water than meat, and were slightly less active than when under normal diet

\begin{tabular}{|c|c|c|c|c|c|c|}
\hline \multicolumn{7}{|c|}{ Normal diet with arterin } \\
\hline Days & Meat & Sugar water & activity & meat & sugar water & activity \\
\hline \multicolumn{7}{|c|}{ Daily counts } \\
\hline IA & I I I I 01 & 12 | 344 & 977789 & 101010 & 101001 & 577788 \\
\hline B & 001100 & 100110 & 546989 & 001100 & 001120 & 566545 \\
\hline II A & I I I I I I & 010111 & 676899 & $0|0| 1 \mid$ & 101111 & 554778 \\
\hline B & I I I I I 0 & 101010 & 545657 & 100010 & 010111 & 454677 \\
\hline III A & I I I 011 & 101222 & 775778 & 001111 & | 22 | | | & 665899 \\
\hline B & 001010 & 001001 & 554768 & 100001 & I I I 222 & 566677 \\
\hline IV A & 111110 & 222223 & 678678 & $101|1|$ & 110223 & 665566 \\
\hline B & 101100 & 111010 & 456568 & 111001 & 111222 & 666667 \\
\hline VA & 001111 & 111011 & 665778 & 001100 & 110110 & 545455 \\
\hline B & 011111 & 001010 & 788799 & 100111 & I I I I I I & 656566 \\
\hline $\mathrm{VIA}$ & 110222 & 011111 & 456768 & 001100 & 001100 & 334564 \\
\hline B & 001111 & 100010 & 566978 & 100010 & 100111 & 566456 \\
\hline \multicolumn{7}{|c|}{ Daily means } \\
\hline I & 0.58 & 1.50 & 7.33 & 0.42 & 0.58 & 6.08 \\
\hline II & 0.92 & 0.58 & 6.42 & 0.50 & 0.75 & 5.75 \\
\hline III & 0.58 & 0.83 & 6.33 & 0.50 & $\mathrm{I} .48$ & 6.67 \\
\hline IV & 0.67 & 1.42 & 6.33 & 0.75 & 1.50 & 5.92 \\
\hline V & 0.75 & 0.58 & 7.25 & 0.50 & 0.83 & 5.17 \\
\hline VI & 1.00 & 0.58 & 6.42 & 0.33 & 0.50 & 4.75 \\
\hline \multicolumn{7}{|c|}{ Average of daily means } \\
\hline & 0.75 & 0.92 & 6.68 & 0.50 & 0.94 & 5.72 \\
\hline
\end{tabular}

Speed of locomotion, sinuosity of movement, pencil drawn on a piece of white paper and divided into 10 angular orientation ability

This was studied on ants walking in their tray; for the two first traits, giving nothing to the ants, for the third trait, presenting them a nestmate tied to a piece of paper (Figure 1A, Figure 1B). Such a tied worker emits its alarm pheromone. Each time, the trajectory of 40 ants was recorded, and all of them were analyzed using a methodology detailed in. ${ }^{20}$ We thus obtained the numerical values of the ants' speed of locomotion, sinuosity of movement, or orientation. These traits are defined in. ${ }^{20}$ For each distribution of 40 values, we established the median and quartiles (Table 2) and the distributions corresponding to ants under arterin diet were compared to those corresponding to ants under normal diet, using the non-parametric $\chi 2$ test. ${ }^{19}$

\section{Trail-following}

Myrmica ant workers produced a trail substance in their poison gland. Ten of these glands were isolated in $500 \mu 1$ hexane and stored for $15 \mathrm{~min}$ at $-25^{\circ} \mathrm{C}$. To perform one experiment, $50 \mu \mathrm{l}$ of the solution was deposited, using a metallic normograph pen, on a circle $(\mathrm{R}=5 \mathrm{~cm})$ degrees arcs. This circular trail was deposited in the ants' tray and the response of 20 workers of colony A and of colony B was quantified by the amount of 10ang.deg. arcs they moved on the trail, continuously (Figure 1B), even if they turned back on their way. The distribution of the recorded numbers was characterized by its median and quartiles (Table 2), and that corresponding to ants under arterin diet was compared to that corresponding to ants having never consumed that food complement thanks to the non-parametric $\chi^{2}$ test.

\section{Audacity}

The apparatus consisted in a tower made of strong white paper (Steinbach, height $=4 \mathrm{~cm}$; diameter $=1.5 \mathrm{~cm}$ ). It was deposited in the ants' tray, and the workers moving on it everywhere were counted 12 times in $12 \mathrm{~min}$. The mean and extremes of the obtained values were established (Table 2) and the values obtained for ants under the two kinds of diet were compared to one another using the nonparametric Wilcoxon test pulling this time the values obtained for the two colonies as well as those obtained during each successive time period of two minutes. ${ }^{19}$ 


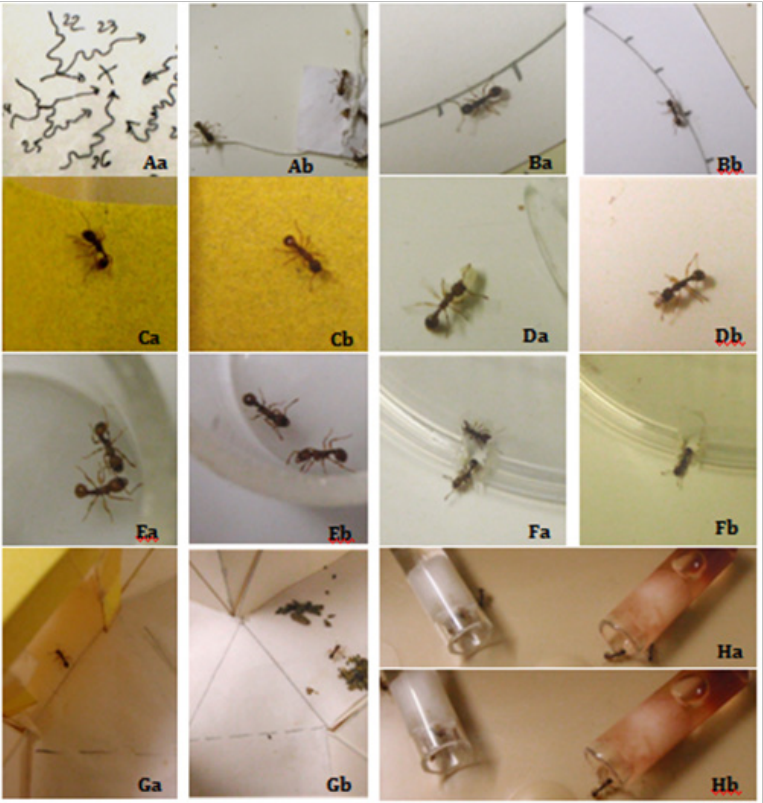

Figure I some views of the experiments. For photos $A$ to $F: A$ : under normal diet, B: under arterin diet; for photos $\mathrm{G}$ and $\mathrm{H}$ : under arterin diet. A: ants' orientation towards an alarm signal (i.e. a tied worker). B: ants' trail following. C: ants moving on a rough substrate. D: ants' brood caring. E: congeners encountering. F: ants escaping from an enclosure. G: trained ants tested in a $\mathrm{Y}$ apparatus provided with the cue in one of its branches. $\mathrm{H}$ : two successive photos of the same experiment; ants presenting no preference between sugar water and sugar water containing arterin (the red liquid) (two ants are drinking sugar water, inside of the not colored tube).

Table 2 Impact of arterin on six ethological and physiological traits. The assessments were made on ants of two colonies being under normal then consuming the drug. Details are given in the text. Briefly, the drug slightly increased the sinuosity of movement, decreased the trail following behavior, and slightly decreased the tactile perception. The tables gives the median (and quartiles) or the mean [and the extremes] of the recorded values. Statistical results can be found in the text. $\mathrm{mm} / \mathrm{s}=$ millimeter per second; ang.deg./ $\mathrm{cm}=$ angular degrees per $\mathrm{cm}$; ang. deg. $=$ angular degrees; $\mathrm{n}^{\circ}=$ number

\begin{tabular}{|c|c|c|}
\hline Traits & normal diet & diet with arterin \\
\hline Linear speed $(\mathrm{mm} / \mathrm{s})$ & $14.4(12.9-15.3)$ & $14.3(\mid 2.9-15.9)$ \\
\hline Angular speed (ang.deg./cm) & $127(\mid 16-139)$ & $142(12 \mid-164)$ \\
\hline Orientation (ang. deg.) & $43 . I(33.5-6 I . I)$ & 43.I(27.2-58.9) \\
\hline Trail following ( ${ }^{\circ}$ arcs) & $9.0(6.0-12.5)$ & $3.5(2.8-8.3)$ \\
\hline Audacity ( $n^{\circ}$ ants) & $0.85[0-2]$ & $1.00[0-2]$ \\
\hline \multicolumn{3}{|l|}{ Tactile (pain) perception: } \\
\hline linear speed $(\mathrm{mm} / \mathrm{s})$ & $6.0(5.0-6.6)$ & $6.8(6.1-7.6)$ \\
\hline angular speed (ang.deg./cm) & $280(253-337)$ & $232(216-244)$ \\
\hline
\end{tabular}

\section{Tactile ("pain") perception}

A physiological adverse effect of a drug may be impacting the sensitive nervous system. It is the reasons why we assessed the ants' locomotion on a rough substrate: if they perceived correctly the uncomfortable character of the substrate, they will walk with difficulties, slowly, sinuously; if their tactile perception is impacted, they will walk more confidently. A folded piece $(3 \mathrm{cmx} 2+7+2 \mathrm{~cm})$ of emery paper $n^{\circ} 280$ was attached to the borders and the bottom of a tray $(15 \mathrm{~cm} \times 7 \mathrm{~cm} \times 4.5 \mathrm{~cm})$. This provided a small smooth zone $(3 \mathrm{~cm}$ long), a zone ( $3 \mathrm{~cm}$ long) where the workers' walking was painful, and a smooth zone ( $9 \mathrm{~cm}$ long). Such an apparatus was built for each colony. Each time, twelve workers were deposited in the first zone. These workers leaving the small zone moved for a moment on the rough substrate (Figure 1C). Under normal diet, ants moved very slowly, with difficulties on that rough substrate; under morphine or other analgesic, they move more frankly, as if they less perceive the uncomfortable character of the substrate. This is why we assessed their locomotion (speed of locomotion, sinuosity of movement; $\mathrm{n}=12 \times 2=24$, (Table 2 ). The values corresponding to ants under arterin diet were compared to those corresponding to ants under normal diet by using the non-parametric $\chi^{2}$ test.

\section{Brood caring}

A few larvae of each colony were removed from their nest and set in front of the entrance. The workers' behavior towards 5 of these larvae was observed (Figure 1D), and the larvae among them not replaced in the nest were counted in the course of 10 experimental minutes. The results obtained for each colony were added (Table 3), and the sums corresponding to ants under arterin diet were compared to those corresponding to ants having never consumed that food complement thanks to the non-parametric Wilcoxon test.

\section{Cognition}

The apparatus used is described in. ${ }^{21}$ Let us repeat that: 'two duly folded pieces of white extra strong paper (Steinbach, $12 \mathrm{~cm} \times 4.5 \mathrm{~cm}$ ) were inserted in a small tray $(15 \mathrm{~cm} \times 7 \mathrm{~cm} \times 4.5 \mathrm{~cm})$ so that a path with twists and turns was created between a loggia too narrow for 15 ants (the initial small loggia) and a larger one (the large loggia)'. Such an apparatus was built for each colony. For colony A and colony B, 15 workers were deposited in the initial loggia. After that, those present in this loggia and those having reached the large loggia were counted in the course of 12 experimental minutes. The results obtained for colony A and colony B were added (Table 3 ). The sums corresponding to ants under arterin diet were compared to those corresponding to ants having never consumed that food complement thanks to the nonparametric Wilcox on test.

\section{Aggressive behavior towards nestmates and aliens}

This treat was quantified in the course of five dyadic encounters for colony A and colony B. Each encountering took place in a cup (diameter $=2 \mathrm{~cm}$, height $=1 \mathrm{~cm}$, the border of which having been covered with talc (Figure $1 \mathrm{E})$. Each time $(5 \times 2=10$ encounters with nestmates as well as with aliens), one ant of colony A or B was observed during five min. The numbers of times it did nothing (= level 0 ), contacted the opponent with its antennae (level 1), widely opened its mandibles (level 2), gripped the opponent (level 3), tried to sting the opponent (level 4) were recorded. The results obtained for each colony were added (Table 3). Those corresponding to ants under arterin diet were compared to those corresponding to ants having never consumed that food complement thanks to the non-parametric $\chi^{2}$ test. The ants' aggressive behavior was also quantified by 'a', a variable which equaled the numbers of recorded levels $2+3+4$ divided by the numbers of recorded levels $0+1$.

\section{Escaping from an enclosure}

For colony A and colony B, six workers were set under a reversed polyacetate glass (height $=8 \mathrm{~cm}$, bottom diameter $=7 \mathrm{~cm}$, ceiling diameter $=5 \mathrm{~cm}$ ) deposited in the ants' tray. The ants were introduced into the reversed glass through a hole (diameter $=3 \mathrm{~mm}$ ) in the center 
of the ceiling. The lower part of the inner surface of the reversed glass had been slightly covered with talc to prevent ants climbing on it The rim of the bottom had been provided with a small notch $(3 \mathrm{~mm}$ height, $2 \mathrm{~mm}$ broad) for giving to the ants the opportunity to escape from the enclosure (Figure 1F). To assess the workers' capability in escaping, we counted, in the course of 12 experimental minutes, those still enclosed and those which could escape. The numbers obtained for colony A and colony B were added (Table 3) and the sums corresponding to ants under arterin diet were compared to those corresponding to ants having never consumed that food complement thanks to the non-parametric Wilcoxon test. We also calculated the variable " $\mathrm{n}$ " of ants escaped after $12 \mathrm{~min} / 12$ " for each kind of diet, 12 being the initial number of imprisoned ants (Table 3 ).

Table 3 Effect of the red yeast of rice on five ethological and physiological traits. Details and statistics are given in the text. Briefly, the examined product did not statistically impact the ants' brood caring behavior, aggressiveness against nestmates and aliens, and escape behavior, but decrease their cognition. Levels of aggressiveness: 0 : doing nothing, I: antennae contacts, 2: mandibles opening, 3: gripping, 4 : stinging or trying to sting; $a=n^{\circ}$ levels $2+3+4 / n^{\circ}$ levels $0+1 . \min =$ minute, $s=$ second

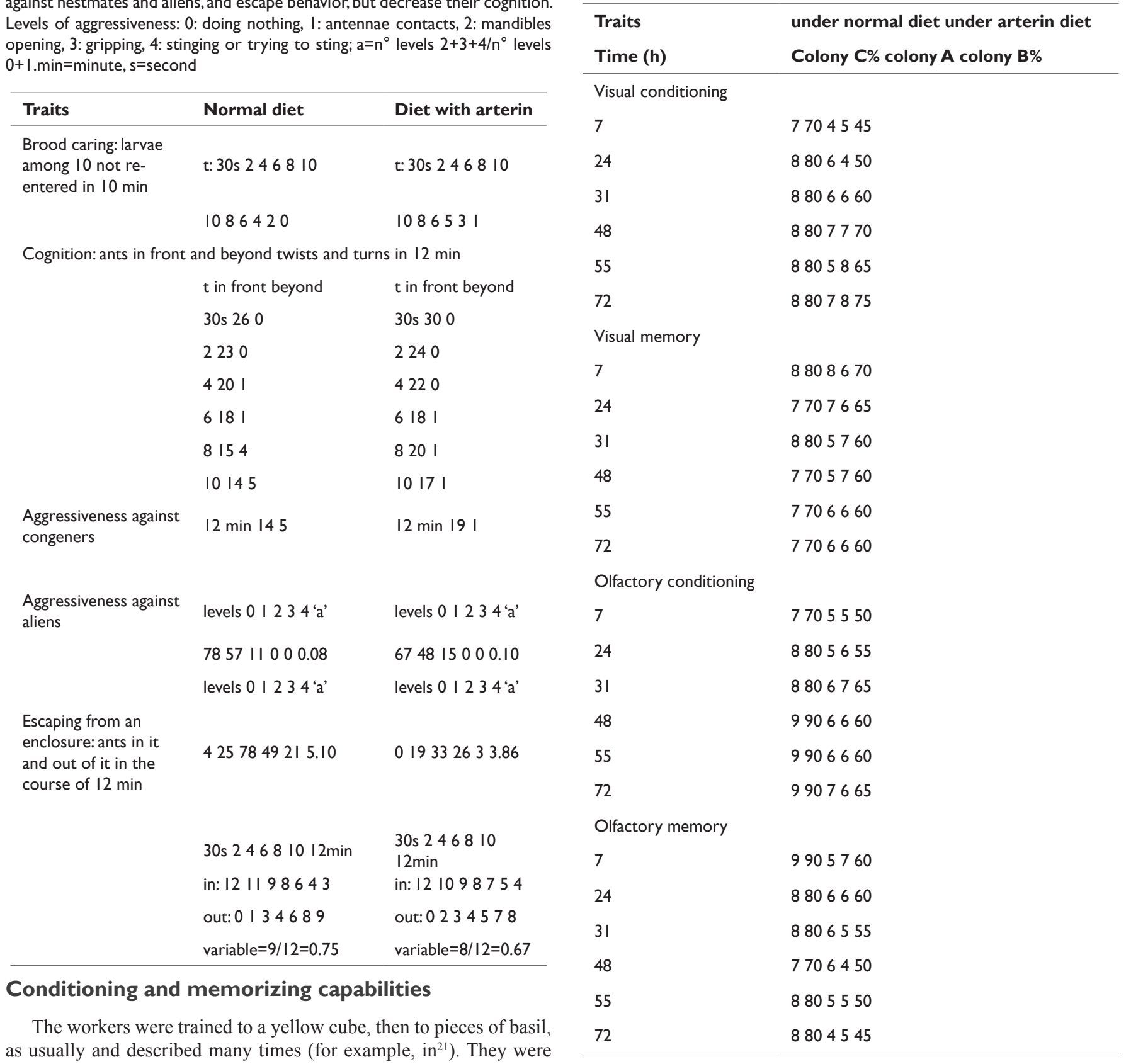

tested in $\mathrm{Y}$ apparatus also as usually and several times explained (i.e. ${ }^{21}$ ) (Figure 1G). These experiments furnished the numbers (and the percentage) of ants giving the correct response in the course of their conditioning acquisition, then of their loss of I (Table 4). Before conducting the present experiment, a control experiment had been made on another colony of the same species never provided with arterin. We did so because, since an individual is trained to a cue, it could no longer be used for any further experiment using that cue. The numbers recorded for ants under arterin diet on one hand and under normal diet on the other hand were compared thanks to the nonparametric Wilcoxon test.

Table 4 Effect of the red yeast of rice on ants' visual and olfactory conditioning ability and on their visual and olfactory memory. The experiment is described, and the statistics are given, in the text. Briefly, the examined product somewhat decreased these ants' traits, impacting thus their short and middle term memory. $\mathrm{H}$, hours; \%, percentage 


\section{Adaptation to arterin}

After 12 days of arterin diet, the ants' angular speed was again assessed exactly as it had been after two days of such a diet in order to examine if ants develop some adaptation to that food complement (Table 5). The distribution of the obtained values was compared to the control distribution and to that of the values recorded after two days of arterin diet thanks to the non parametric $\chi^{2}$ test.

Table 5 Adaptation and habituation to effects of arterin on ants' physiology. The ants' sinuosity of movement, and tactile perception, were again assessed after fifteen days of arterin consumption for examining if ants adapted themselves, and became habituated to the impact of arterin on these traits. Briefly, the ants developed adaptation but no habituation to arterin consumption. Details and statistics are given in the text. ang.deg/cm=angular degrees per centimeter, $\mathrm{mm} /$ $s=$ millimeter per second

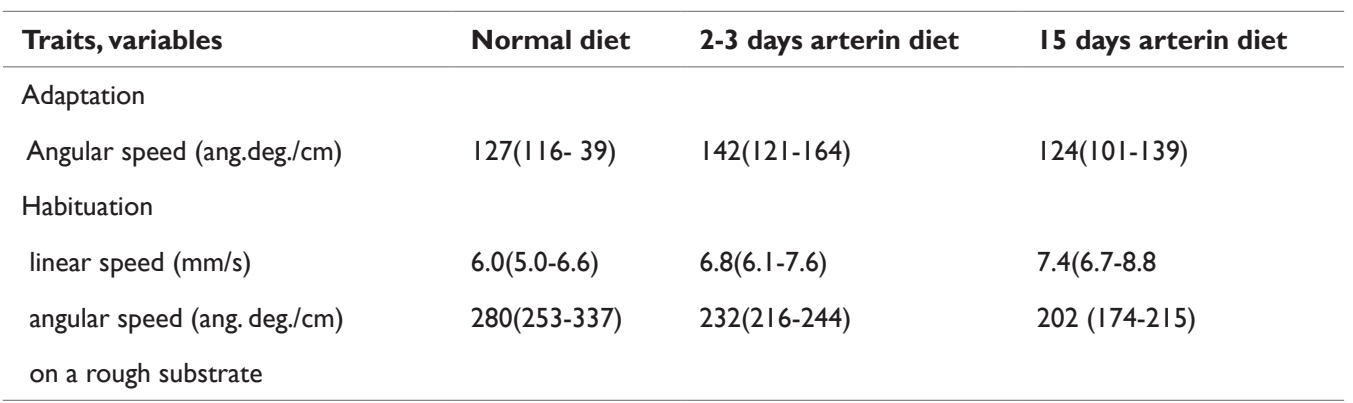

\section{Habituation to arterin}

After having lived under arterin diet during 13 days, the workers' pain perception was again assessed just like it has been assessed after four days of consumption in order to examine if ants develop some habituation to a physiological effect of the product here revealed, i.e. some reduction of pain perception (Table 5). Thanks to the nonparametric $\chi^{2}$ test, the results were compared to the control ones and to those corresponding to four days under arterin diet.

\section{Dependence on arterin consumption}

After the ants had consumed arterin for 14 days, we conducted an experiment for revealing if ants developed any physical dependence on that food complement. The methodology has already been used for several examined products, and is described in previous papers (for example in ${ }^{18,21,22}$ ) (Figure $1 \mathrm{H}$ ). In fine, the obtained results were compared to those which had occurred if ants presented no dependence on arterin, thanks to the non-parametric goodness of fit $\chi^{2}$ test. ${ }^{19}$

\section{Loss of the effects of arterin after weaning}

A fresh solution of arterin was provided to the two colonies, and was replaced by a solution of pure sugar 12 hours later. Since that weaning time, the ants' pain perception was assessed exactly as it has been assessed while ants were under normal or arterin diet, this after several time periods. The distributions of values obtained after some time periods were compared to those obtained after 4 days of arterin consumption and to those corresponding to ants having never consumed arterin using the non-parametric $\chi^{2}$ test. The numerical results are detailed in (Table 6), and the median values are graphically presented in (Figure 2). The experiment ended when the ants' tactile perception was again similar to that they exhibited under normal diet.

\section{Results and discussion}

\section{Meat sugar, intake and active state}

The ants consumed somewhat less meat (thus proportionally more sugar one) when being under arterin diet than when being under normal diet (Table 1). This observation was slightly statistically significant: meat: $\mathrm{N}=6, \mathrm{~T}=-19.5,0.031<\mathrm{P}<0.047$; sugar water: $\mathrm{N}=6$, $\mathrm{T}=+13.5, \mathrm{P}<0.344)$. The ants were also less active while consuming arterin (Table 1), and this result was significant $(\mathrm{N}=6, \mathrm{~T}=-20$,
$\mathrm{P}=0.031$ ). Arterin impacted thus the ants' general activity and food consumption. These traits were assessed during six days without any amelioration (on the contrary for the general activity). It can thus be deduced that no habituation occurred, in the course of time, as for the impact of the food complement on these traits.

\section{Linear and angular speed}

Numerical results are given in Table 2, lines 1, 2. Comparatively with the situation under normal diet, the ants consuming arterin walked at a similar linear speed $(43.1 \mathrm{~mm} / \mathrm{s}$ vs $44.4 \mathrm{~mm} / \mathrm{s})$ but with a slightly larger sinuosity (142ang.deg./cm vs 127 ang.deg./cm), the latter difference being however not statistically significant $\left(\chi^{2}=6.74\right.$, $\mathrm{df}=3,0.05<\mathrm{P}<0.10)$. Arterin affected thus very slightly the ants' locomotion.

\section{Orientation ability}

Arterin did not impact the ants' orientation ability (Table 2), line 3; 43.1ang.deg vs 43.1ang.deg). Under that food additive, the ants moved towards a source of alarm pheromone (i.e. a tied congener) as efficiently as when under normal diet (Figure 1A). They might take some more time for reacting and reaching the tied worker, but this time parameter was not quantified.

\section{Trail following}

This trait was a little affected by arterin consumption (Table 2), line 4. Indeed, under this product consumption, the ants meanly followed a circular trail along only $3.5 \operatorname{arcs}$ of $10^{\circ}$ while under normal diet, the meanly followed such a trail along 9.0 arcs of $10^{\circ}$. This difference between the two diets was significant: $\chi^{2}=20.57, \mathrm{df}=3, \mathrm{P}<0.001$. The food complement impacted thus the ants' ability of going on moving along a circular line though they obviously perceived the trail pheromone and followed the trail for a time (Figure 1B). This observation agreed with the ants' tendency to walk more sinuously than usually (see above).

\section{Audacity}

The workers' audacity was not impacted by arterin (Table 2), line 5. The variable assessing this trait meanly equaled 1.00 and 0.85 for ants consuming this food complement and the same ants having never done so respectively. The difference between the two series of recorded values was not significant $(\mathrm{N}=3, \mathrm{~T}=5, \mathrm{NS})$. 


\section{Tactile (pain) perception}

Such a perception was slightly impacted by arterin (Table 2), line 6, (Figure 1D). Indeed, workers not consuming this food complement walked very cautiously on emery paper, at a low linear speed (meanly $6.0 \mathrm{~mm} / \mathrm{s}$ ) with a high sinuosity (meanly 280ang.deg./cm). While consuming arterin, they went on moving slowly, though not so slowly (meanly $6.8 \mathrm{~mm} / \mathrm{s} ; \chi^{2}=3.23, \mathrm{df}=2, \mathrm{P}=0.20$ ) but with a not so large sinuosity (meanly 232 ang.deg. $/ \mathrm{cm} ; \chi^{2}=16.63, \mathrm{df}=2, \mathrm{P}<0.001$ ). In fact, the workers less avoided the unpleasant character of the emery paper. Arterin may thus slightly decrease their tactile (pain?) perception, acting probably on their nervous system and general physiology.

\section{Brood caring}

This trait was, at first sight, not affected by arterin consumption (Table 3), line 1, (Figure 1D). The workers consuming this food complement went on taking care of their larvae and nymphs, and replaced in the nest those experimentally set outside just like they did when under normal diet $(\mathrm{N}=3, \mathrm{~T}=6, \mathrm{NS})$. The only difference between normal and arterin diets was that workers under the latter diet had difficulty in loading large larvae and nymphs. They could not load them in the usual, far from the ground, position and were thus unable to transport them easily. However, they obviously went onto them, took care of them, and transported or tried to transport them into the nest. The difference between normal and arterin diets was not a difference of relation between the individuals of the colony but a difference of physical ability in loading heavy material. Let us add here an observation made all along the experimental work and not quantified: the ants appeared to have some difficulties in loading a corpse (in order to transport it far from the nest). The two above observations may indicate an impact of the food complement on the muscles functioning.

\section{Cognition}

This trait was impacted by arterin (Table 3 ) line 2. While ants did not consumed arterin, 5 ones among 30 reached the large loggia beyond the difficult path, and only 14 ones still remained in front of it after the 12 experimental minutes. Under arterin diet, only one ant reached the large loggia, and 19 ones still moved in front of the difficult path after the 12 minutes. The difference between normal and arterin diets was significant: small loggia: $\mathrm{N}=6, \mathrm{~T}=21, \mathrm{P}=0.016$; large loggia: $\mathrm{N}=4, \mathrm{~T}=-10, \mathrm{P}=0.06$. Arterin appeared thus to affect the ants' cognition. In fact, under that food complement diet, ants entered the difficult path but often came back on their way, and therefore did not reach the large loggia beyond that difficult path. This is the second experiment revealing an impact of the examined food complement on the ants' nervous system (see above 'Tactile (pain?) perception').

\section{Aggressiveness against nestmates and aliens}

These traits were not affected by arterin consumption (Table 3 ) line 3, (Figure 1E). In presence of a nestmate, an ant under arterin diet behaved just like an ant under normal diet. It often stayed near its nestmate doing nothing, or it touched it with its antennae; it seldom slightly opened its mandibles. The variable assessing this behavior equaled 0.08 and 0.10 for workers under normal and arterin diet respectively. The difference of behavior between ants under each kind of diet was not significant: $\chi^{2}=1.45, \mathrm{df}=2,0.30<\mathrm{P}<0.50$. In presence of an alien (a worker from another colony of M. sabuleti), an ant not consuming arterin as well as an ant under this food complement diet aggressed the alien. It seldom stayed inactive; it often contacted the alien with its antennae, and very frequently opened its mandibles.
It also often gripped the alien and sometimes tried to sting it. The variable assessing this behavior equaled 5.10 and 3.86 for ants having never consumed arterin and ants under arterin diet respectively. The latter ants were thus somewhat less aggressive than the former ones. In fact, they simply behaved with some delay and were consequently soon attacked by the aliens. However, the difference between normal and arterin diets was not significant: $\chi^{2}=1.90, \mathrm{df}=2,0.30<\mathrm{P}<0.50$. Thus, arterin did not affect the social relation between nestmates and aliens. This result agreed with the workers' normal care of brood while being under arterin diet (see above 'brood caring').

\section{Ability in escaping from an enclosure}

Arterin somewhat impacted this trait but such a result was not significant (Table 3) line 4, (Figure 1F). Under normal diet, 9 ants among 12 could escape from the enclosure and 3 ones were still captive after 12 minutes. Under arterin diet, 4 ants could escape, and 8 ones could not. The variable assessing these events equaled $3 / 4=0.75$ for ants not consuming arterin and $1 / 3=0.66$ for ants doing so. The latter ants were thus less able in finding the exit of the enclosure within 12 minutes. They might have found it a little later. In any way, the difference in ants' escaping ability when under each kind of diet was not significant. For the ants which escaped, we obtained $\mathrm{N}=4, \mathrm{~T}=-7.5,0.188<\mathrm{P}<0.313$, and for ants still captive, $\mathrm{N}=4, \mathrm{~T}=+7.5$, $0.188<\mathrm{P}<0.313$. Arterin affected thus very slightly the ants' ability in finding rapidly an exit of an enclosure and in going out of that enclosure. This might result from some impact of the food complement on the nervous system, a presumption already had twice in the present work (see above 'Tactile (pain) perception', 'Cognition').

\section{Conditioning and memorizing capabilities}

Arterin appeared to affect these physiological traits (Table 4, Figure $1 \mathrm{G})$. Workers not consuming arterin reached $70 \%$ of visual conditioning in 7 hours and of $80 \%$ in 24 hours. Under arterin diet, they reached $50 \%$ of visual conditioning in 24 hours, and finally $75 \%$ in 72 hours. The difference between normal and arterin diets was significant: $\mathrm{N}=6, \mathrm{~T}=-21, \mathrm{P}=0.016$. The difference was large during the first hours of training and became smaller in the course of the training. The ants under arterin diet may thus learn the visual cue simply more slowly than ants which did not consumed this food complement. This might result from a less efficient memory. After removal of the visual cue, the workers under normal diet lost $0 \%$ of their conditioning after 7 hours, and only $10 \%$ of it after 72 hours. Under arterin diet, they lost $5 \%$ in 7 hours, $15 \%$ after 31 as well as 72 hours. The difference of memory between ants under one and the other kind of diet was significant: $\mathrm{N}=5, \mathrm{~T}=15, \mathrm{P}=0.031$. Arterin affected thus weakly the ants' short and middle term visual memory. Another proof of this statement is that the ants that have stayed a long time under the yellow cube, drinking or not the sugar water, very often correctly responded, while those that have not gone near the cue for a long time generally randomly responded. The ants' visual memory was thus, clearly, somewhat decreased.

sConcerning the olfactory memory, ants under normal diet reached $70 \%$ of conditioning after 7 hours of training, as well as $90 \%$ after 48 and 72 hours. Under arterin diet, the ants reached $50 \%$ and $65 \%$ of conditioning after identical time periods of training. The difference between ants under normal and arterin diets was significant: $\mathrm{N}=6$, $\mathrm{T}=-21, \mathrm{P}=0.016$. Arterin affected the ants' olfactory conditioning, and thus their short term memory. After removal of the olfactory cue, ants under normal diet kept all their conditioning during 7 hours without training, and lost only $10 \%$ of it after 72 hours. In fact, they 
successively lost $0 \%, 10 \%, 0 \%, 10 \%,-10 \%$, and $0 \%$. Under arterin diet, the ants lost $5 \%$ of their conditioning in 7 hours and a total of $20 \%$ in 72 hours. In fact, they successively lost $5 \%, 0 \%, 5 \%, 5 \%, 0 \%$, and $5 \%$. The difference in the loss of conditioning between ants under the two kinds of diet was not significant: $\mathrm{N}=6, \mathrm{~T}=+8,-13, \mathrm{P}=0.344$. Arterin affected thus only very slightly the ants' middle term olfactory memory.

In any way, the above related experiments revealed some impact of the examined food complement on the ants' nervous system, a fact we experienced already three times in the course of the present work (see above: Tactile (pain) perception', 'Cognition', 'ability in escaping from an enclosure').

\section{Adaptation to arterin}

The workers' sinuosity (affected by arterin consumption) was again assessed after they were consuming this food complement during 15 days (Table 5). This trait then meanly equaled 124ang. deg./cm, while it equaled $127 \mathrm{ang} . \mathrm{deg} . / \mathrm{cm}$ as long as the ants did not consumed arterin, and 142 ang.deg./cm after they had consumed the food complement for one day. Statistically, the value obtained after 15 days of arterin consumption did not differ from the control one $\left(\chi^{2}=1.44, \mathrm{df}=3,0.50<\mathrm{P}<0.70\right)$ but was not yet fully different from that presented after one day of consumption i.e. it was at the limit of significance $\left(\chi^{2}=8.11, \mathrm{df}=4,0.05<\mathrm{P}<0.10\right)$. Consequently, the ants progressively adapted themselves to some effects of arterin, and were about to be adapted as for the impact of arterin on their sinuosity of movement after 15 days of consumption.

\section{Habituation to arterin consumption}

The ants' movement on emery paper (modified under arterin consumption) was again assessed after the ants had consumed arterin for 15 days (Table 5). The linear speed meanly equaled $7.4 \mathrm{~mm} / \mathrm{s}$ and the angular speed 202 ang.deg. $/ \mathrm{cm}$, while these traits meanly equaled $6.0 \mathrm{~mm} / \mathrm{s}$ and $280 \mathrm{ang}$.deg./ $/ \mathrm{cm}$ under normal diet as well as 6.8 $\mathrm{mm} / \mathrm{s}$ and 232ang.deg./ $\mathrm{cm}$ after 3 days of arterin consumption. The difference of ants' sinuosity on rough substrate between ants having consumed arterin for 15 days and ants under normal diet was highly significant $\left(\chi^{2}=33.87, \mathrm{df}=3, \mathrm{P}<0.01\right)$ : the ants went on less perceiving the discomfort of the rough substrate. Moreover, the sinuosity of ants having consumed arterin for 15 days was even slightly lower than that of ants having consumed the food complement for 5 days $\left(\chi^{2}=5.98\right.$, $\mathrm{df}=2, \mathrm{P}=0.05$ ): the workers' 'pain' perception was thus slightly more and more reduced in the course of arterin consumption. Consequently, the ants develop no habituation (on the contrary!) to arterin effect on their tactile perception, and thus on their sensorial physiology. Let us add that the workers' olfactory conditioning was examined after 10-13 days of arterin consumption, and that this ability was impacted by the product. There was thus no habituation to arterin impact on the nervous system, and probably on the physiology in general.

\section{Dependence on arterin consumption}

In front of sugar water containing arterin and sugar water free of that food complement, 8 workers of colony A were seen drinking the former liquid while 10 workers were observed on the latter liquid, and 26 ants of colony B went drinking the latter liquid while 20 ants were seen drinking the former liquid. In total, 28 ants preferred the liquid containing arterin while 36 ants preferred that free of it. These numbers were not statistically different from those which would have occurred if ants randomly drank each provided sugar liquid, i.e. 32 and $32\left(\chi^{2}=1.99, \mathrm{df}=1,0.10<\mathrm{P}<0.20\right)$. Thus, the ants did not develop any dependence on arterin consumption (Figure 1H).

\section{Loss of the effects of arterin after weaning}

The variable used for examining this decrease was the ants' angular speed on emery paper, affected by arterin. The results are presented in (Table 6) and (Figure 2). During the four first hours following weaning, this variable did not change, on the contrary. Having again given some fresh solution of arterin to the ants 8 hours before weaning, it could be presumed that the food additive reaches its full activity after a time period of about 10 hours. Four hours after weaning, the effect of arterin began to decrease. This decrease was slow, essentially between 10 and 14 hours after weaning. Statistically, after $7 \frac{1}{2}$ hours, the workers' sinuosity on emery paper still differed from the control one $\left(\chi^{2}=13.20, \mathrm{df}=2,0.001 \sim \mathrm{P}<0.01\right)$, and similar to that initially presented $\left(\chi^{2}=4.39, \mathrm{df}=2,0.10<\mathrm{P}<0.20\right)$. After $10^{1 / 2}$ hours, this sinuosity still differed from the control one $\left(\chi^{2}=6.50, \mathrm{df}=2\right.$, $0.02<\mathrm{P}<0.05)$, but, this time, different from that initially presented $\left(\chi^{2}=8.69, \mathrm{df}=2,0.01<\mathrm{P}<0.02\right)$. Seven teen hours after weaning, the ants' sinuosity was again statistically different from that initially presented $\left(\chi^{2}=6.19, \mathrm{df}=2,0.02<\mathrm{P}<0.05\right)$, but this time, statistically similar (though not yet strictly identical) to the control one $\left(\chi^{2}=2.03\right.$, $\mathrm{df}=2,0.10<\mathrm{P}<0.20$ ). After 25 hours, the assessed variable had a value identical to the control one. The effect of arterin decreased according to a logarithmic function of the running time, from 4 hours until 25 hours after weaning. The function can be written as: et $=\mathrm{ei}-\mathrm{k} \log \mathrm{t}$ ( $\mathrm{e}=\mathrm{effect}, \mathrm{t}=$ time, $\mathrm{k}=\mathrm{a}$ constant) (see (Figure 2$)$, right graph). In this figure, the point $\mathrm{t}=0$ has been replaced by $\mathrm{t}=10 \mathrm{~min}$ (the time period of a test $)=0.166 \mathrm{~h}$, so that its Logarithm (O.22) could be represented. The loss of the physiological effect of arterin was thus slow, being in fact slower and slower in the course of the running time. This allows avoiding addiction on the product consumption, as it has often been shown all along our studies on the effects of products consumed by humans, ;,18,21,22 Cammaerts, unpublished data].

Table 6 Decrease of the physiological effect of arterin after its consumption was stopped. Since the weaning, the ants' sinuosity of movement on a rough substrate was assessed. A latency period of 4 hours occurred. Then, the variable progressively reached the control value, in a total of 25 hours, changing according to a logarithmic function of the running time. This event is graphically presented in (Figure 2). The table gives the median (and quartiles) of the ants' sinuosity. More details are given in the text. ang.deg. $/ \mathrm{cm}=$ angular degrees per centimeter. vs $=$ versus, $\chi^{2}=$ chi square, $\mathrm{P}=$ level of probability

\begin{tabular}{|c|c|c|}
\hline Time (hours) & $\begin{array}{l}\text { Ants' sinuosity on } \\
\text { a rough substrate } \\
\text { (ang.deg./cm) }\end{array}$ & $\begin{array}{l}\text { Statistics (non parametric } \\
\chi^{2} \text { test) }\end{array}$ \\
\hline $\log _{\text {time }}-4 h$ & & vs $\mathrm{t}=0$ vs control \\
\hline 0 & $202(174-215)$ & \\
\hline 2 & $200(163-226)$ & \\
\hline 4 & $195(165-210)$ & \\
\hline $71 / 20.54$ & $219(193-251)$ & $0.10<P<0.200 .001 \sim P<0.01$ \\
\hline $101 / 20.81$ & $246(194-269)$ & $0.01<P<0.020 .02<P<0.05$ \\
\hline $131 / 20.97$ & $248(216-270)$ & \\
\hline 171.11 & $268(232-292)$ & $0.02<P<0.050 .10<P<0.20$ \\
\hline $25 \quad 1.32$ & $280(260-314)$ & \\
\hline control & $280(253-337)$ & \\
\hline
\end{tabular}


Table 7 Comparison of the ethological and physiological effects of simvastatin (socor) and of lovastatin (arterin), two products which are (largely for the former, scarcely for the latter) used to care of persons suffering from hypercholesterolemia. Details are given in the text, 7. Discussion, Conclusion. Brielfly, arterin has far less adverse effects than simvastatin, and should thus preferentially be used for persons who have a moderately high level of cholesterol. $h=h o u r s$

\begin{tabular}{lll}
\hline Traits & Simvastatine(socor) & Lovastatin(arterin) \\
\hline Meat consumption & no impact & very slight decrease \\
Sugar water consumption & large increase & very slight increase \\
General activity & some decrease & slight decrease \\
Linear speed & some decrease & no impact \\
Angular speed & increase & slight increase \\
Orientation ability & large decrease & no impact \\
Trail following behavior & decrease & decrease \\
Audacity & large decrease & no impact \\
Tactile (pain) perception & large decrease & slight decrease \\
Brood caring behavior & impacted & no impact \\
Cognition & largely impacted & some impact \\
Aggressiveness against nestmates & no impact & no impact \\
Aggressiveness against aliens & slight decrease & no impact \\
Ability in escaping & large decrease & slight decrease \\
Visual conditioning acquisition & large impact & impact \\
Visual memory & large impact & slight impact \\
Olfactory conditioning acquisition & large impact & impact \\
Olfactory memory & large impact & slight impact \\
Adaptation & occurs & occurs \\
Habituation & does not occur & does not occurs \\
Dependence & no dependence & no dependence \\
Decrease of the effects & slow, regular & 4 h latency, slow and slower \\
\hline & & \\
\hline
\end{tabular}
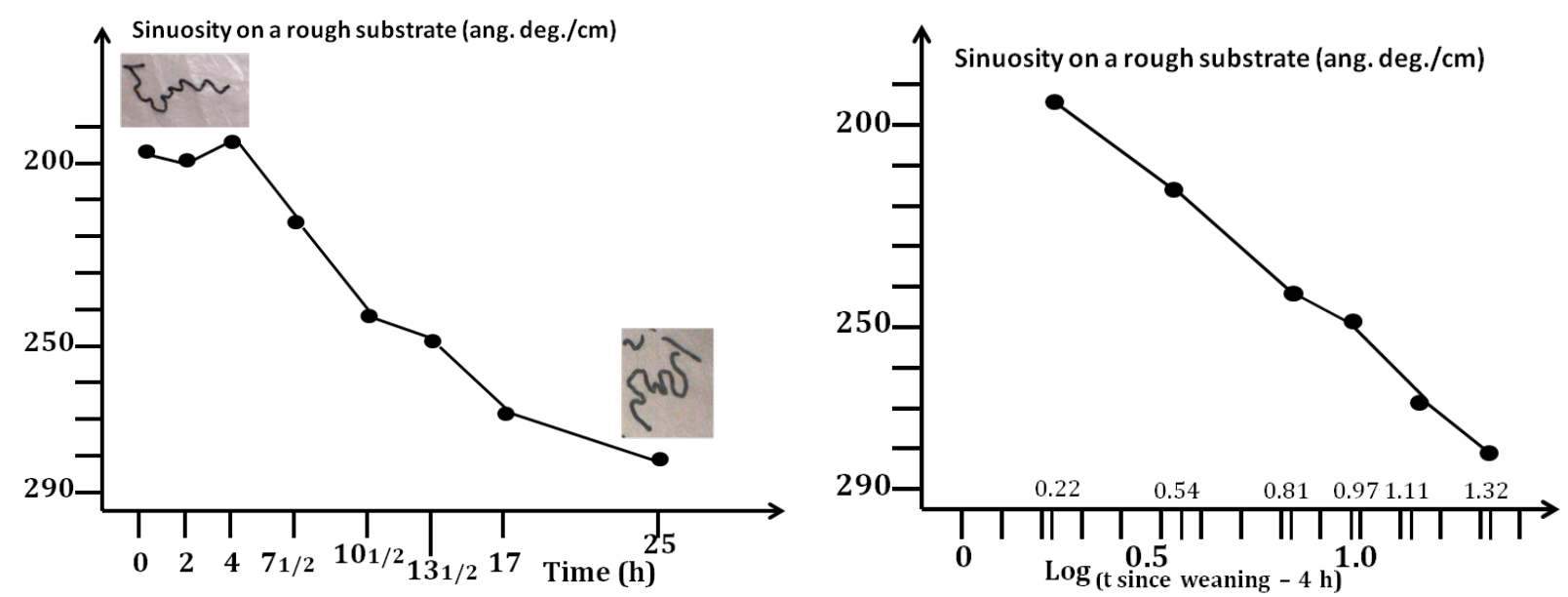

Figure 2 Decrease of the physiological effects of arterin after its consumption was stopped. After a latency period of 4 hours, the effect of the food additive decreased slowly, according to a logarithmic function of the running time, and vanished in 25 hours. Numerical results and statistics are given in Table 7; details can be found in the text. On the right graph, the point $\mathrm{t}=4-4$ hours has been replaced by $\mathrm{t}=10$ minutes $(=0.166)$ so that its Log could be represented on the graph. ang.deg./cm = angular degrees per centimeter, $\mathrm{h}=$ hours, $\mathrm{t}=$ time. 


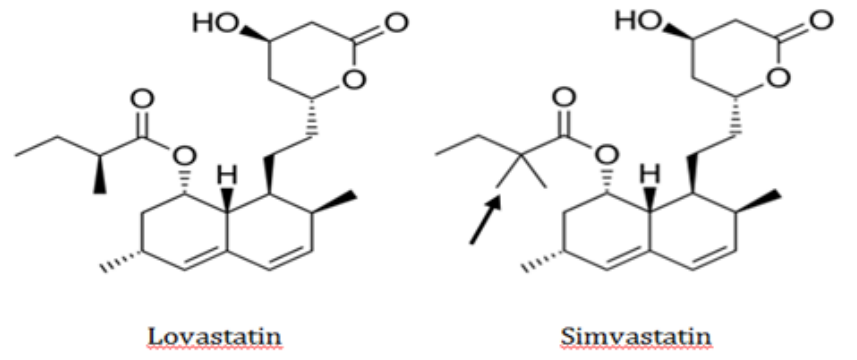

Figure 3 Chemical structure of lovastatin (the statin present in the here examined natural product, the red yeast of rice) and of simvastatin (a previously examined synthesized statin). The latter substance has a methyl more (arrow) than the former one.

\section{Conclusion}

The present work, on ants as models, revealed that the red yeast of rice, a food complement which could be used for treating persons suffering from hypercholesterolemia, present a few adverse effects: slight effect on food consumption, general activity, sinuosity of movement, trail following, tactile perception, cognition, ability in escaping, visual and olfactory conditioning. These effects result from an impact of the product (namely arterin) on the muscles functioning and on the nervous system. They are due to the statin lovastatin. They are similar to those presented by the largely used synthesized statins (example, simvastatin). This is logical since the two kinds of molecule are nearly identical (Figure 3). The formula of arterin is C24 H36 O5 while that of simvastatine is $\mathrm{C} 25 \mathrm{H} 38 \mathrm{O}$. The two substances are complex butanoate, lovastatin being a 2 methyl one, and simvastatin a 2,2 dimethyl one. However, differences as for their adverse effects appeared between the two kinds of product (Table 6). Working exactly in the same way while examining the effects of these two products, we can compare them. We noted 11 adverse effects for the food complement and 16 ones for simvastatin. The former product did not impact the workers' speed of locomotion, orientation ability, audacity, brood caring, aggressiveness against aliens, while simvastatin did so. Moreover, the harmful effects of arterin were of lower intensity than those also presented by simvastatin (impact on food consumption, activity, sinuosity of movement, trail following, tactile perception, cognition, ability in escaping, conditioning to and memory of visual and olfactory cues). On the other, like and even better than simvastatin, arterin leaded to some adaptation, to no habituation, and to no dependence, and, after weaning, its effects slowly vanished with time. Consequently, we advance that, for treating persons suffering from moderate hypercholesterolemia (who are the predominate patients), the use of the natural red yeast of rice is preferable to that of artificially produced statins (such a simvastatin, which can be used for treating severe hypercholesterolemia) because it generates less adverse effects and effects of lower intensity.

Looking to works already made on the effects of the red yeast of rice (after having finished our experiments, being thus blind to the situation), we discovered that this food additive has very often been proved to lower the amount of cholesterol in blood, without having any or very few adverse effects ${ }^{23-31}$ among others]. Some of these works compare the effect of the red yeast of rice to those of synthesized statins, and are in favor of the former product, as we were at the end of our present work. However, some harmful impacts on muscles functioning have also been reported in a few published works. ${ }^{32-36}$ We have also revealed such an impact in our present work. We also observed a slight impact on the nervous system, but this observation has never been reported, until now, by other researchers. In fact, adequate tests have never been performed to check this potential effect. In any way, this slight impact of the red yeast of rice was far lower than that previously observed for simvastatin. Consequently, on the basis of our works and of those of other researchers and practitioners, we definitively conclude that the red yeast of rice should be advantageously used, instead of synthesized statins, for treating persons suffering from hypercholesterolemia.

\section{Acknowledgements}

None.

\section{Conflict of interest}

The author declares no conflict of interest.

\section{References}

1. Wagstaff LR, Mitton MW, Arvik BM, et al. Statin-associated memory loss: analysis of 60 case reports and review of the literature. Pharmacotherapy. 2003;23(7):871-880.

2. Cammaerts MC, Cammaerts D. Physiological effects of statins; a study on ants as models. A J P R H C, submitted

3. Sathasivam S, Lecky B. Statin induced myopathy. BMJ. 2008. 337 p.

4. https://www.topsante.com

5. http://www.e-sante.fr/quelles-plantes-contre-cholesterol/ actualite/1234\#khzvhCIJTCWx5GGo.99

6. Huang CF, Li TC, Lin CC, et al. Efficacy of Monascus purpureus Went rice on lowering lipid ratios in hypercholesterolemic patients. Eur $J$ Cardiovasc Prev Rehabil. 2007;14(3):438-440.

7. http://eurekasante.vidal.fr/parapharmacie/complements-alimentaires/ levure-riz-rouge-monascus-purpureus.html\#T9LMq8rzwY9Cexrm.99

8. Wehner R, Gehring W. Animal biology and physiology. De Boek University, Paris, Brussels: Thieme Verlag; 1999. 844 p.

9. Wolf FW, Heberlein U. Invertebrate models of drug abuse. J Neurobiol. 2003;54(1):161-178.

10. Andre RG, Wirtz RA, Das YT. Insect models for biomedical research. In: Woodhead AD, editors. Non mammalian Animal Models for Biomedical Research. Boca Raton, FL: CRC Press; 1989. p. 62-70.

11. Keller RA. A phylogenetic analysis of ant morphology (Hymenoptera: Formicidae) with special reference to the Poneromorph subfamilies. Bull Am Museum Nat Hist. 2011;355:1-90.

12. Billen J, Morgan ED. Pheromone communication in social insts sources and sretions. In: Vander Meer RK, et al. editors. Pheromone Communication in Social Insts: Ants, Wasps, Bees, and Termites. Oxford. Boulder: Westview Press; 1998

13. Hölldobler B, Wilson EO. The ants. Harvard University Press, Berlin: Springer-Verlag; 1990. $732 \mathrm{p}$

14. Passera L, Aron S. Les fourmis: comportement, organisation sociale et evolution: Ottawa Canada: Les Presses Scientifiques du CNRC; 2005. $480 \mathrm{p}$.

15. Cammaerts MC, Cammaerts D. Comparative outlook over three Myrmica species' biotopes and foragers' know-how. Biologia. 2014;69(8):10511058.

16. Cammaerts MC, Cammaerts R. Ontogenesis of ants' cognitive abilities (Hymenoptera, Formicidae). Adv Stud Biol. 2015;7:335-348.

17. Cammaerts MC, Gosset G. Impact of age, activity and diet on the conditioning performance in the ant Myrmica ruginodis used as a biological model. Int J Biol. 2014;6(2):10-20. 
18. Cammaerts MC. Ants as biological models for studying effects of substances used by humans. JSM Anat Physiol. 2016;1(1):1003

19. Siegel S, Castellan NJ. Non-parametric statistics for the behavioural sciences. Singapore: McGraw-Hill Book Company; 1989. 396 p.

20. Cammaerts MC, Morel F, Martino F, et al. An easy and cheap softwarebased method to assess two-dimensional trajectories parameters. Belg $J$ Zool. 2012;142:145-151.

21. Cammaerts MC, Gosset G, Rachidi Z. Some physiological and ethological effects of nicotine; studies on the ant Myrmica sabuleti as a biological model. Int J Biol. 2014;6:64-81.

22. Cammaerts MC, Rachidi Z, Gosset G. Physiological and ethologica effects of caffeine, theophylline, cocaine and atropine; study using the ant Myrmica sabuleti (Hymenoptera, Formicidae) as a biological model. Int J Biol. 2014;3:64-84.

23. Lu GP, Huo Sh Q. Comparison of the effects of Xuezhikang with simvastatin on lipid profile modification in patients with hypercholesterolemia. Chinese J Int Med. 1998;7(6):371-373.

24. $\mathrm{Lu} \mathrm{ZL}, \mathrm{Xu} \mathrm{S}$, Kou W. The clinical observation of treatment of hyperlipidemia with different dose of Xuezhikang. National Symposium of Clinical Therapies for Cardiovascular Diseases. 1997. p. 53-57.

25. Ma YL. Observation of 30 cases of hypercholesterolemia in treatment with Xuezhikang. J Pract Trad Chinese Med. 2002;18(3):48.

26. Ong HT, Cheah JS. Statin alternatives or just placebo: an objective review of omega-3, red yeast rice and garlic in cardiovascular therapeutics. Chin Med J (Engl). 2008;121(16):1588-1594.

27. Shen G, Wang J, Wang JF. Comparison of the effects of the herbal lipid regulator decoction, Xuezhikang and simvastatin on lipid modulation in the middle-aged and elderly subjects with hyperlipidemia. Zhongguo Jiceng Yiyao. 2000;7(4):280-281.
28. Zheng Y, Luo XZ, Wang SL, et al. Clinical controlled study on the therapeutic effects of Xuezhikang and Simvastatin. Zhongguo Yaoshi. 2001;36(10):715

29. Bliznakov EG. More on the Chinese red-yeast-rice supplement and its cholesterol-lowering effect. Am J Clin Nutr. 2000;71(1):152-157.

30. Gheith O, Sheashaa H, Abdelsalam M, et al. Efficacy and safety of Monascus purpureus Went rice in children and young adults with secondary hyperlipidemia: a preliminary report. Eur J Intern Med. 2009;20(3):e57-61.

31. Changling L. Monascus purpureus-fermented rice (red yeast rice): a natural food product that lowers blood cholesterol in animal models of hypercholesterolemia. Nutr Res. 1998;18(1):71-81.

32. Smith DJ, Olive KE. Chinese red rice-induced myopathy. South Med J. 2003;96(12):1265-1267.

33. Wu LC, Chen YC, Ho JA, et al. Inhibitory effect of red koji extracts on mushroom tyrosinase. J Agric Food Chem. 2003;51(15):4240-4246.

34. Vercelli L, Mongini T, Olivero N, et al. Chinese red rice depletes muscle coenzyme Q10 and maintains muscle damage after discontinuation of statin treatment. J Am Geriatr Soc. 2006;54(4):718-720.

35. Lapi F, Gallo E, Bernasconi S, et al. Myopathies associated with red yeast rice and liquorice: spontaneous reports from the Italian Surveillance System of Natural Health Products. Br J Clin Pharmacol. 2008;66(4):572-74.

36. Changling L, Yafang L, Zhonglin H. Toxicity study for monascus purpureus (red yeast) extract. Chin Pharmacol Soc. 1995;12(4):12. 